\title{
Growth hormone deficiency after treatment of acute leukaemia in children
}

\author{
S. M. SHALET, C. G. BEARDWELL, P. H. MORRIS JONES, AND D. PEARSON \\ From the Departments of Medicine, Paediatrics, and Radiotherapy, Christie Hospital and Holt Radium \\ Institute, Manchester
}

\begin{abstract}
Shalet, S. M., Beardwell, C. G., Morris Jones, P. H., and Pearson, D. (1976). Archives of Disease in Childhood, 51, 489. Growth hormone deficiency after treatment of acute leukaemia in children. Growth hormone (GH) secretion was studied in 15 children at various times after treatment for acute lymphatic leukaemia. Impaired GH responses both to hypoglycaemia and to Bovril were found in 4 children. 13 of the children had been given prophylactic cranial irradiation of either 2500 rads in 10 fractions or 2400 rads in 20 fractions. The reduction in GH responses in those given the former dose was highly significant compared with the reduction in those given the latter dose. However, other differences between the two groups included the length of time since cranial irradiation and the chemotherapy used. The main cause of the GH deficiency is not yet clear, but we conclude that it may occur in children treated successfully for acute lymphatic leukaemia.
\end{abstract}

Short stature is a recognized sequel to the treatment of brain tumours in children (Bamford et al., 1976; Onoyama et al., 1975). Growth hormone (GH) deficiency seems to be common in such patients (Shalet et al., 1975) and may well be a major aetiological factor. Children with brain tumours are treated by a variety of methods, including chemotherapy, neurosurgery, and radiotherapy. The cause of GH deficiency has not yet been elucidated but radiotherapy is thought to play an important role. The recently improved prognosis in acute lymphatic leukaemia in childhood is partly owed to the introduction of prophylactic cranial irradiation (Aur et al., 1972). It therefore seemed worthwhile to see whether this treatment affected GH secretion.

\section{Patients and methods}

Fifteen prepubertal children who had been treated for acute lymphatic leukaemia were studied. Only one of the 15 was still being treated with a cytotoxic agent and all had been in complete clinical remission for at least three years. Clinical details of the 15 patients are shown in Table $I$.

The drugs given in the UKALL I protocol are prednisolone, vincristine, 6-mercaptopurine, asparaginase, cytosine arabinoside, and methotrexate. The

Received 22 October 1975. only additional chemotherapeutic agent given in UKALL II is cyclophosphamide. In the Memphis Total Therapy $\mathrm{V}$ protocol the drugs are prednisolone, vincristine, methotrexate, 6-mercaptopurine, and cyclophosphamide, while the Concord protocol includes all these except cyclophosphamide but adds asparaginase.

The object and exact nature of the studies were explained to the children and their parents and their consent obtained before investigations were started. Standing and sitting heights were measured with a stadiometer. Bone age was estimated using the atlas of Greulich and Pyle (1959). Plain skull $x$-ray films were taken to estimate pituitary fossa size in order to exclude coincidental disease affecting the hypothalamic-pituitary region.

An insulin tolerance test was carried out on all the children after an overnight fast. Soluble insulin $(0.2$ units $/ \mathrm{kg})$ was given intravenously after the basal blood samples had been taken. Venous blood for the estimation of $\mathrm{GH}$, cortisol, and glucose was withdrawn at 30-minute intervals over a period of 2 hours. Estimations of serum thyroid-stimulating hormones (TSH), thyroxine $\left(T_{4}\right)$, and tri-iodothyronine $\left(T_{3}\right)$ were made on basal blood samples. GH secretion after an oral dose of Bovril (Jackson, Grant, and Clayton, 1968) was also measured.

Plasma cortisol was measured fluorimetrically (Mattingly, 1962) and blood glucose by the neocuproine method (Brown, 1961). Serum TSH, $T_{3}, T_{4}$ and GH were measured by double antibody radioimmunoassay, MRC standard $68 / 38$ was used in the TSH assay and $66 / 217$ in the GH assay. 
TABLE I

Clinical details of patients studied and amount of irradiation (DXT)

\begin{tabular}{|c|c|c|c|c|c|c|}
\hline Case no. & Sex & $\begin{array}{l}\text { Age at } \\
\text { study } \\
\text { (years) }\end{array}$ & $\begin{array}{c}\text { Time since } \\
\text { cranial DXT } \\
\text { (years) }\end{array}$ & $\begin{array}{l}\text { Cranial } \\
\text { DXT } \\
\text { (rad) }\end{array}$ & $\begin{array}{l}\text { Spinal } \\
\text { DXT } \\
\text { (rad) }\end{array}$ & Chemotherapy protocol \\
\hline $\begin{array}{c}1 \\
2 \\
3 \\
4 \\
5 \\
6 \\
7 \\
8 \\
9 \star \\
10 \\
11 \\
12 \\
13 \\
14 \\
15\end{array}$ & $\begin{array}{c}M \\
M \\
M \\
F \\
F \\
F \\
M \\
F \\
M \\
M \\
M \\
M \\
M \\
F \\
M\end{array}$ & $\begin{array}{r}10 \cdot 3 \\
7 \cdot 3 \\
11 \cdot 0 \\
8 \cdot 6 \\
8 \cdot 2 \\
7 \cdot 7 \\
8 \cdot 3 \\
8 \cdot 4 \\
7 \cdot 0 \\
5 \cdot 7 \\
11 \cdot 3 \\
6 \cdot 0 \\
8 \cdot 9 \\
4 \cdot 8 \\
8 \cdot 3\end{array}$ & $\begin{array}{l}4 \cdot 4 \\
4 \cdot 3 \\
5 \cdot 0 \\
4 \cdot 5 \\
4 \cdot 5 \\
5 \cdot 0 \\
5 \cdot 4 \\
4 \cdot 2 \\
2 \cdot 3 \\
2 \cdot 6 \\
3 \cdot 4 \\
3 \cdot 7 \\
3 \cdot 4 \\
2 \cdot 6 \\
-\end{array}$ & $\begin{array}{c}2500 \\
2500 \\
2500 \\
2500 \\
2500 \\
2500 \\
2500 \\
2500 \\
2400 \\
2400 \\
2400 \\
2400 \\
2400 \\
1720 \\
-\end{array}$ & $\begin{array}{c}1000 \\
1000 \\
1000 \\
1000 \\
1000 \\
1000 \\
- \\
- \\
2400 \\
2400 \\
2400 \\
2400 \\
2400 \\
1600 \\
-\end{array}$ & $\begin{array}{l}\text { Concord and Memphis } \\
\text { Total Therapy V } \\
\text { UKALL I } \\
\text { UKALL I } \\
\text { UKALL I } \\
\text { UKALL I } \\
\text { UKALL I } \\
\text { Memphis Total Therapy V } \\
\text { Memphis Total Therapy V } \\
\text { UKALL II } \\
\text { UKALL II } \\
\text { UKALL II } \\
\text { UKALL II } \\
\text { UKALL IJ } \\
\text { UKALL II } \\
\text { Concord }\end{array}$ \\
\hline
\end{tabular}

*Patient still receiving intermittent 6-mercaptopurine.

\section{Results}

Adequate hypoglycaemia, as defined by the presence of hypoglycaemic symptoms and a blood sugar nadir of $2 \cdot 2 \mathrm{mmol} / 1$ or less, was obtained in each child. Data obtained in our laboratory show that normal children and adults attain a GH peak of $20 \mathrm{mU} / 1$ after such a stimulus (Shalet et al., 1975). The peak GH responses to both hypoglycaemia and Bovril are shown in Table II. 6 of the children showed an impaired GH response to an insulin tolerance test (ITT), while in 7 the $\mathrm{GH}$ response to Bovril was inadequatc - that is $<20 \mathrm{mU} / \mathrm{l}$.

It is generally accepted that children with normal $\mathrm{GH}$ production may fail to respond to a single test
(Raiti, Davis, and Blizzard, 1967; Weldon et al., 1973) and that GH deficiency should be presumed only if failure of response is seen in at least two different tests. By this criterion only 4 out of the 15 children can be assumed to be GH deficient.

In Cases 1 to 82500 rads had been delivered to the midplane of the cranium in 14 days (10 fractions), whereas in Cases 9 to 13 a dose of 2400 rads had been given in 27 days ( 20 fractions). All the patients had received homogeneous irradiation throughout the cranium and there were few deviations from the planned duration of treatment. In order to compare the effects of these two radiation regimens the children were divided into two

TABLE II

Bone age, standing and sitting heights, peak GH responses to an insulin-tolerance test (ITT) and a Bovril stimulation test in 15 patients studied

\begin{tabular}{|c|c|c|c|c|c|}
\hline Case no. & $\begin{array}{l}\text { Bone } \\
\text { age } \\
\text { (years) }\end{array}$ & $\begin{array}{l}\text { Standing } \\
\text { height } \\
\text { (centile) }\end{array}$ & $\begin{array}{l}\text { Sitting } \\
\text { height } \\
\text { (centile) }\end{array}$ & $\begin{array}{c}\text { Peak GH reponse } \\
\text { to ITT } \\
(\mathrm{mU} / \mathrm{l})\end{array}$ & $\begin{array}{c}\text { Peak GH response } \\
\text { to Bovril } \\
(\mathrm{mU} / \mathrm{l})\end{array}$ \\
\hline $\begin{array}{r}1 \\
2 \\
3 \\
4 \\
5 \\
6 \\
7 \\
8 \\
9 \\
10 \\
11 \\
12 \\
13 \\
14 \\
15\end{array}$ & $\begin{array}{r}10 \cdot 0 \\
6 \cdot 0 \\
9 \cdot 0 \\
4 \cdot 0 \\
5 \cdot 9 \\
7 \cdot 5 \\
8 \cdot 3 \\
7 \cdot 8 \\
5 \cdot 6 \\
7 \cdot 0 \\
11 \cdot 3 \\
5 \cdot 0 \\
9 \cdot 0 \\
3 \cdot 0 \\
8 \cdot 0\end{array}$ & $\begin{array}{r}50-75 \\
25-50 \\
10-25 \\
<3 \\
10-25 \\
25-50 \\
10 \\
50-75 \\
<3 \\
>97 \\
<3 \\
10-25 \\
10-25 \\
<3 \\
25-50\end{array}$ & $\begin{array}{r}50-75 \\
<3 \\
10-25 \\
<3 \\
10 \\
10-25 \\
10-25 \\
50-75 \\
<3 \\
>97 \\
<3 \\
3 \\
3-10 \\
<3 \\
25-50\end{array}$ & $\begin{array}{r}17 \cdot 5 \\
15 \cdot 7 \\
23 \cdot 4 \\
3 \cdot 9 \\
16 \cdot 3 \\
13 \cdot 9 \\
1 \cdot 8 \\
22 \cdot 4 \\
39 \cdot 9 \\
63 \cdot 0 \\
43 \cdot 0 \\
88 \cdot 6 \\
75 \cdot 0 \\
21 \cdot 7 \\
91 \cdot 3\end{array}$ & $\begin{array}{r}3 \cdot 2 \\
16 \cdot 9 \\
22 \cdot 0 \\
15 \cdot 8 \\
24 \cdot 6 \\
57 \cdot 4 \\
4 \cdot 0 \\
28 \cdot 6 \\
3 \cdot 9 \\
49 \cdot 0 \\
35 \cdot 4 \\
11 \cdot 9 \\
46 \cdot 5 \\
27 \cdot 5 \\
17 \cdot 0\end{array}$ \\
\hline
\end{tabular}


groups according to the type of irradiation received. The maximum GH levels attained, irrespective of the test used, were then compared between the two groups, as shown in Table III. A Mann-Whitney

\section{TABLE III}

Peak GH response in 13 patients who had received cranial irradiation

\begin{tabular}{c|c}
\hline \multicolumn{2}{c}{ Peak GH response (mU/1) } \\
\hline $2500 \mathrm{rad}(10$ fractions) & $2400 \mathrm{rad}$ (20 fractions) \\
\hline $17 \cdot 5$ & $39 \cdot 9$ \\
$16 \cdot 9$ & $63 \cdot 0$ \\
$23 \cdot 4$ & $43 \cdot 0$ \\
$15 \cdot 8$ & $88 \cdot 6$ \\
$24 \cdot 6$ & $75 \cdot 0$ \\
$57 \cdot 4$ & \\
$4 \cdot 0$ & \\
$28 \cdot 6$ & \\
\hline
\end{tabular}

$\mathrm{U}$ test showed a highly significant difference $(\mathbf{P}=$ $0 \cdot 006)$. Standing and sitting heights were estimated using standard charts (Tanner, Whitehouse, and Takaishi, 1966), and the centile height at the time of study of each child is shown in Table II.

Thirteen of the patients had received spinal irradiation, and at least 5 had overt skeletal disproportion with impaired spinal growth. In 2 out of the 4 patients (Cases 1,7) with GH deficiency the bone age was consistent with chronological age. In the other cases the bone age was retarded by 16 months (Case 2) and 54 months (Case 4) respectively.

Fig. 1 shows the growth chart in Case 4, the only girl with GH deficiency. During the period of chemotherapy the growth velocity fell away from the 3rd centile and appeared to recover a little over the year after the cessation of all therapy. However, over the last 1.4 years the growth velocity fell away again, perhaps related to the $\mathrm{GH}$ deficiency.

Fig. 2 shows the growth chart of Cases 1, 2, and 7 , the 3 boys with GH deficiency. During the latter half of chemotherapy the growth velocity fell away in each and when the drugs were stopped there were no pronounced changes. However, the longest period off all therapy for these subjects was 2 years (Case 7).

The peak cortisol response to insulin hypoglycaemia was normal in each child and none were hypothyroid, either clinically or biochemically. $X$-ray examination of the pituitary fossa showed no abnormality.

\section{Discussion}

Reports of the effect of long-term antileukaemic therapy on growth are conflicting. Sundermann

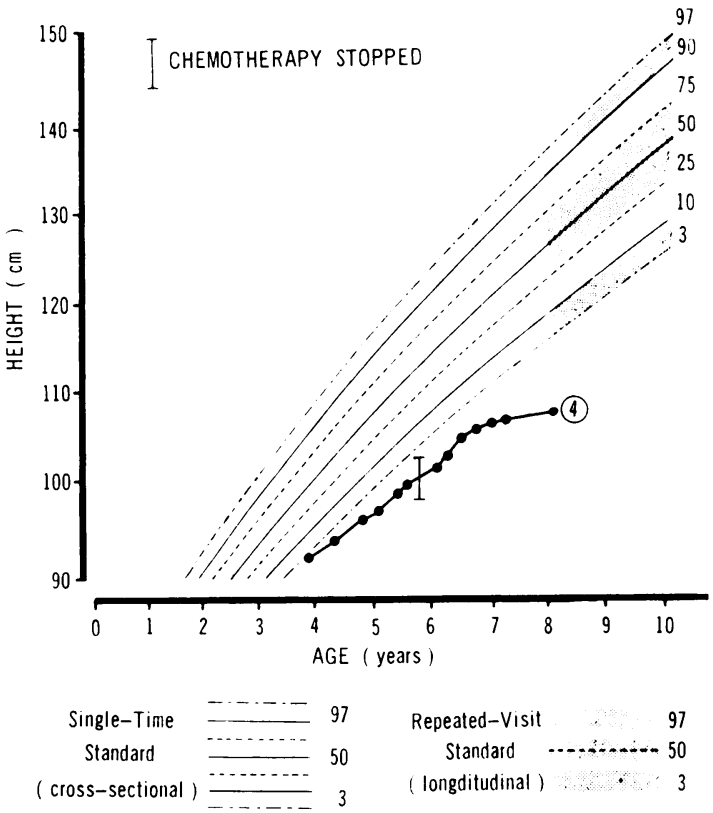

FIG. 1.-Growth curve of girl (Case 4) with biochemical evidence of $G H$ deficiency.

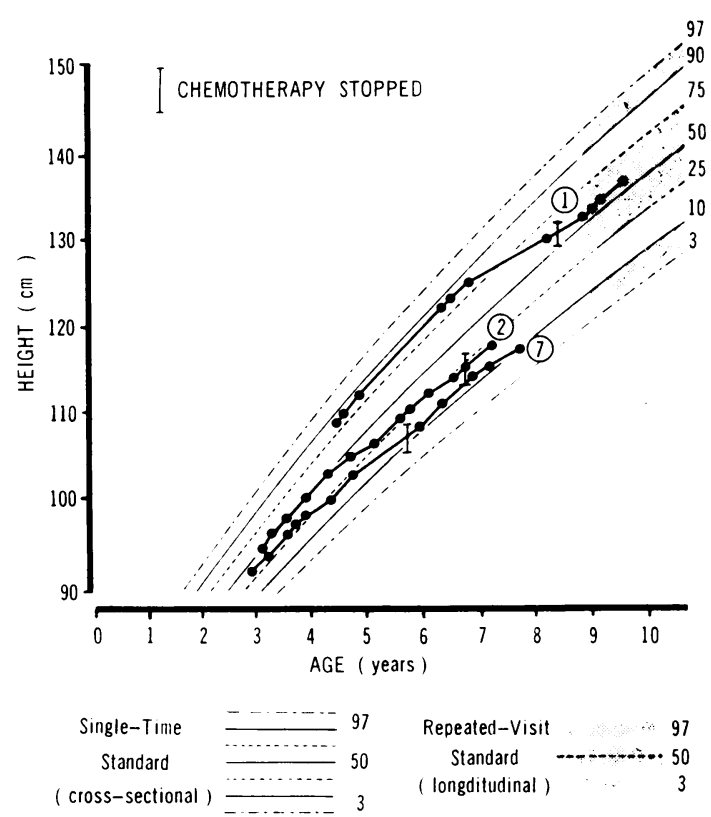

FIG. 2.-Growth curves of 3 boys (Cases 1, 2, 7) with biochemical evidence of $G H$ deficiency. 
and Pearson (1969) studied 21 children who had continuous chemotherapy for 18 months or more but no radiotherapy. All of their patients had linear growth rates parallel to those of normal children. Pinkel (1971), however, described 3 children whose growth rates decreased while they were receiving treatment. After chemotherapy was discontinued their height increments increased, so that within three years their heights were at or above the initial centiles. In 2 other children linear growth rate was reduced during therapy, and this continued after treatment was stopped. The children in Pinkel's study (1971) received cranial irradiation plus more intensive chemotherapy than those described by Sundermann and Pearson (1969).

Most of our 15 children showed a decrease in linear growth, particularly towards the latter part of their chemotherapy. This may have been due to the disease, the intensive chemotherapy, or the spinal irradiation. The 3 boys with impaired GH responses showed no evidence of any pronounced change in their growth rates when the chemotherapy ceased. The only girl with impaired $\mathrm{GH}$ responses had a growth rate which, a year after the chemotherapy stopped, continued to decline away from the 3rd centile, as is typically seen in GH deficiency. Insufficient time has elapsed as yet to enable us to determine whether growth rates in the children with apparent GH deficiency differ from those of the children whose $\mathrm{GH}$ responses appear to be normal, so that we cannot yet be certain whether the impaired GH responses are biologically significant.

We have previously shown (Shalet et al., 1975) that in children receiving treatment for intracranial tumours there is a progressive decline in the $\mathrm{GH}$ response to hypoglycaemia with increasing time after initial treatment. This makes it difficult to determine the exact time at which $\mathrm{GH}$ production falls below normal. However, in two of the boys (Cases 1,7) with impaired GH responses the lack of bone age retardation suggests that it is of recent occurrence. In the same group of children treated for intracranial tumours we found that the median peak GH level after hypoglycaemia was significantly blunted within 3 months of starting therapy compared to that of normal children, though still within the normal range. Dacou-Voutetakis et al. (1975) reported a significant fall in mean GH concentrations after three weeks of cranial irradiation (2400 $\mathrm{rad}$ ) in children with acute leukaemia.

In our group there was a difference in the $\mathrm{GH}$ response according to the cranial irradiation regimen. Children who received 2500 rads in 10 fractions showed a highly significant reduction in
GH response compared to those who received 2400 rads in 20 fractions. However, although the former group received a higher effective biological dose of radiation it cannot necessarily be assumed that this was the only cause of the greater reduction in $\mathrm{GH}$ output. Children receiving the higher dose were all treated before the others and their lower GH responses could, therefore, simply reflect the length of time elapsed since treatment was completed. Furthermore, the chemotherapeutic regimens in the two groups, though similar, had certain subtle differences.

Whatever is the major factor in the aetiology of the reduced $\mathrm{GH}$ production probably an increasing number of children with acute lymphatic leukaemia will be at risk of developing $\mathrm{GH}$ deficiency over the next few years. With the great advances made in the prognosis of children with acute lymphatic leukaemia much more attention has been focused on the quality of their survival. This must include the detection and treatment of GH deficiency when appropriate.

We thank Mr. M. Palmer for statistical advice.

\section{RBFBRBNCBS}

Aur, R. J. A., Simone, J. V., Hustu, H. O., and Verzosa, M. S. (1972). A comparative study of central nervous system irradiation and intensive chemotherapy early in remission of childhood acute lymphocytic leukemia. Cancer, 29, 381.

Bamford, F. N., Morris-Jones, P. H., Pearson, D., Ribeiro, G. G., Shalet, S. M., and Beardwell, C. G. (1976). Residual disabilities in children treated for intracranial space occupying lesions. Cancer, 37, 1149.

Brown, M. E. (1961), Ultra-micro sugar determinations using 2, 9-dimethyl- 1, 10-phenanthroline hydrochloride (neocuproine.) Diabetes, 10, 60.

Dacou-Voutetakis, C., Xypolita, A., Chaidas, St., Constantinidis, M., and Zannos-Mariolea, L. (1975). Irradiation of the head. Immediate effect on growth hormone secretion in childhood. Pediatric Research, 8, 686.

Greulich, W. W., and Pyle, S. I. (1959). Radiographic Atlas of Skeletal Development of the Hand and Wrist. Stanford University Press, Stanford.

Jackson, D., Grant, D. B., and Clayton, B. E. (1968). A simple oral test of growth-hormone secretion in children. Lancet, 2, 373.

Mattingly, D. J. (1962). A simple fluorimetric method for the estimation of free 11-hydroxycorticoids in human plasma. fournal of Clinical Pathology, 15, 374.

Onoyama, Y., Abe, M., Takahashi, M., Yabumoto, E., and Sakamoto, T. (1975). Radiation therapy of brain tumors in children. Radiology, 115, 687.

Pinkel, D. (1971). Five-year follow-up of 'total therapy' of childhood lymphocytic leukemia. Fournal of the American Medical Association, 216, 648.

Raiti, S., Davis, W. T., and Blizzard, R. M. (1967). A comparison of the effects of insulin hypoglycaemia and arginine infusion on release of human growth hormone. Lancet, $2,1182$.

Shalet, S. M., Beardwell, C. G., Morris Jones, P. H., and Pearson, D. (1975). Pituitary function after treatment of intracranial tumours in children. Lancet, $2,104$. 
Sunderman, C. R., and Pearson, H. A. (1969). Growth effects of long-term antileukemic therapy. Journal of Pediatrics, 75, 1058 .

Tanner, J. M., Whitehouse, R. H., and Takaishi, M. (1966). Standards from birth to maturity for height, weight, height velocity and weight velocity: British children, 1965. Archives of Disease in Childhood, 41, 613.

Weldon, V. V., Gupta, S. K., Hammond, M. W., Pagliara, A. S. Jacobs, L. S., and Daughaday, W. H. (1973). The use of
L-dopa in the diagnosis of hyposomatotropism in children. fournal of Clinical Endocrinology and Metabolism, 36, 42.

Correspondence to Dr. S. M. Shalet, Department of Medicine, Christie Hospital and Holt Radium Institute, Manchester 20. 